\title{
INCLUSÃO ESCOLAR DE JOVENS E ADULTOS COM DEFICIÊNCIA: VIVÊNCIAS E POSSIBILIDADES NA ESCOLA PÚBLICA
}

\author{
Gerda de Souza Holanda ${ }^{1}$ \\ Marcelino Arménio Martins Pereira ${ }^{2}$ \\ Sónia Cristina Mairos Ferreira ${ }^{3}$
}

\section{RESUMO}

Este estudo emerge das leituras e discussões envolvendo a inclusão educacional de jovens e adultos com deficiência na escola regular do estado Ceará e se configura como uma ferramenta para a reflexão sobre os papéis desempenhados por gestores, professores e alunos no processo de inclusão desses alunos, bem como sobre a responsabilidade da escola na promoção de uma educação de qualidade para todos. Este estudo, cujo objetivo é analisar a situação de desenvolvimento do processo de inclusão de jovens e adultos com deficiência na escola pública brasileira, especificamente no contexto do estado do Ceará, a partir do exame de como as ações de apoio a esses alunos têm sido geridas por gestores e professores, com vistas à aprendizagem significativa e ao bem-estar do aluno, assim como

\footnotetext{
1 Doutora pela Universidade de Coimbra, Coimbra, Portugal. Diretora do Memorial da Universidade Federal do Ceará e Professora da Rede Pública Estadual do Ceará. ORCID: https://orcid.org/0000-0001-5881-6238. E-mail: gerda.holanda@gmail.com

2 Doutor em Psicologia da Reabilitação. Professor Associado da Universidade de Coimbra, Coimbra, Portugal. Integra a equipa do Laboratório de Avaliação Psicológica e Psicometria da FPCEUC. Membro integrado do CINEICC da FPCEUC, no grupo de investigação Neuropsychological Assessment and Ageing Processes. ORCID: https://orcid.org/0000-0002-1468-2124.E-mail: marcpereira@fpce.uc.pt

${ }^{3}$ Doutora em Educação Permanente e Formação de Adultos, em Ciências da Educação. Especialista em Antropologia Humanitária, Engajamento Humanitário e Promoção da Saúde nos Médicos Sem Fronteiras. Professora Auxiliar da Universidade de Coimbra, Coimbra, Portugal. Coordenadora da Divisão M da APCdP (Associação Portuguesa Conversas de Psicologia). ORCID: https://orcid.org/0000-0003-2240-3700. E-mail: smairosferreira@fpce.uc.pt
} 
das perspectivas dos alunos sobre o processo de inclusão na escola regular noturna, está vinculado ao projeto de doutorado desenvolvido na Universidade de Coimbra, que aborda a inclusão escolar de alunos com deficiência na modalidade Educação de Jovens e Adultos (EJA). Os resultados evidenciam que as mudanças não conseguem incluir todas as pessoas, em todas as suas necessidades e continuam privilegiando alguns, enquanto excluem sistematicamente muitos outros, exigindo um redesenho do contexto educacional brasileiro, que privilegie as experiências e saberes dos alunos e intensifique as relações com as comunidades onde o processo educativo se consolida.

Palavras-chave: Escola Regular Noturna. Educação de Jovens e Adultos. Inclusão de Alunos com Deficiência.

\section{SCHOOL INCLUSION OF YOUTH AND ADULTS WITH DISABILITIES: EXPERIENCES AND POSSIBILITIES IN PUBLIC SCHOOL}

\section{ABSTRACT}

This study emerges from readings and discussions involving the educational inclusion of young people and adults with disabilities in regular schools in the state of Ceará and is configured as a tool for reflection on the roles played by managers, teachers and students in the process of inclusion of these students, as well as on the school's responsibility in promoting quality education for all. This study, whose objective is to analyze the situation of development of the process of inclusion of young people and adults with disabilities in Brazilian public schools, specifically in the context of the state of Ceará, from an examination of how actions to support these students have been managed by managers and teachers, with a view to meaningful learning and student well-being, as well as the students' perspectives on the inclusion process in the regular night school, is linked to the doctoral project developed at the University of Coimbra, which addresses the inclusion of students with disabilities in the Education of Young People and Adults (EJA) modality. The results show that the 
changes cannot include all people, in all their needs and continue to privilege some, while systematically excluding many others, requiring a redesign of the Brazilian educational context, which privileges students' experiences and knowledge and intensify relations with the communities where the educational process is consolidated.

Keywords: Regular Night School. Education for Youths and Adults. Inclusion of Students with Disabilities.

\section{INCLUSIÓN ESCOLAR DE JÓVENES Y ADULTOS CON DISCAPACIDAD: EXPERIENCIAS $Y$ POSSIBILIDADES EM LA ESCUELA PÚBLICA}

\section{RESUMEN}

Este estudio surge de lecturas y discusiones que involucran la inclusión educativa de jóvenes y adultos con discapacidad en las escuelas regulares del estado de Ceará y se configura como una herramienta de reflexión sobre los roles que desempeñan los directivos, docentes y estudiantes en el proceso de inclusión de estos, así como sobre la responsabilidad de la escuela de promover una educación de calidad para todos. Este estudio, cuyo objetivo analizar la situación de desarrollo del proceso de inclusión de jóvenes y adultos con discapacidad en las escuelas públicas brasileñas, específicamente en el contexto del estado de Ceará, a partir de un examen de cómo se han gestionado las acciones de apoyo a estos estudiantes, por administradores y profesores, con miras a un aprendizaje significativo y el bienestar de los estudiantes, así como las perspectivas de los estudiantes sobre el proceso de inclusión en la escuela nocturna regular, está vinculado al proyecto de doctorado desarrollado en la Universidad de Coimbra, que aborda la inclusión de estudiantes con discapacidad en la modalid Educación de Jóvenes y Adultos (EJA). Los resultados muestran que los cambios no pueden incluir a todas las personas, en todas sus necesidades y seguir privilegiando a algunas, mientras que excluyen sistemáticamente a muchas otras, requiriendo un rediseño del contexto educativo brasileño, que privilegie las experiencias y conocimientos de los 
estudiantes e intensifique las relaciones con las comunidades donde se consolida el proceso educativo.

Palabras clave: Escuela Nocturna Regular. Educación para Jóvenes y Adultos. Inclusión de Estudiantes con Discapacidad.

\section{INTRODUÇÃO}

A partir de 2011, com a criação do Plano Nacional dos Direitos da Pessoa com Deficiência, por meio do Decreto No 7.612, de 17 de novembro de 2011 (BRASIL, 2011), o Governo Federal evidencia o compromisso com os direitos das pessoas com deficiência ${ }^{4}$, com vistas a possibilitar-Ihes igualdade na realização de seus sonhos e na concretização de seus projetos.

Para atender a esse compromisso, é necessário que o primeiro e mais definitivo passo diga respeito à educação sem discriminação, pois este é um direito inalienável que, junto à formação ao longo da vida, compõe o processo de aquisição e renovação do conhecimento na contemporaneidade.

Educação e formação ao longo da vida são processos que estimulam a ligação entre a escola e o mercado de trabalho e são promotoras do crescimento pessoal e social do indivíduo. Neste texto, entende-se educação como o processo de escolaridade obrigatória, enquanto a formação é um processo que oportuniza o desenvolvimento pessoal e profissional ao longo da vida, com vistas a melhorar a qualidade de vida do indivíduo e da coletividade.

Com o desejo de colaborar com a temática, este trabalho emerge das leituras e discussões envolvendo a inclusão educacional de jovens e adultos com deficiência na escola regular noturna do estado Ceará, propiciadas pelo itinerário formativo e investigativo desenvolvido no Doutoramento em Ciências da Educação da Universidade de Coimbra, especialidade em Educação, Desenvolvimento Comunitário e Formação de Adultos, e se configura

\footnotetext{
${ }^{4} \mathrm{O}$ termo 'pessoa com deficiência' é a forma oficial de se referir às pessoas com deficiência do Brasil, de acordo com a Lei Brasileira de Inclusão (BRASIL, 2015).
} 
como uma ferramenta para a reflexão sobre os papéis desempenhados por gestores, professores e alunos no processo de inclusão desses alunos, bem como sobre a responsabilidade da escola na promoção de uma educação de qualidade para todos.

A partir dessa intencionalidade, o estudo teve, por objetivo geral, analisar a situação de desenvolvimento do processo de inclusão de jovens e adultos com deficiência na escola pública brasileira, especificamente no contexto do estado do Ceará, a partir do exame de como as ações de apoio a esses alunos têm sido geridas por gestores e professores, com vistas à aprendizagem significativa e ao bem-estar do aluno, assim como das perspectivas dos alunos sobre o processo de inclusão na escola regular noturna.

Ao retratar o contexto de trabalho dos gestores e professores da escola pública cearense, no âmbito da Educação de Jovens e Adultos (EJA), o estudo ora apresentado destaca questões relativas ao contexto da inclusão nessa modalidade de ensino, assim como a identificação, à luz da gestão escolar, dos entraves e alternativas de solução para a efetivação do processo de inclusão na instituição escolar. Destaca, ainda, a realidade dos professores no que concerne às tentativas empíricas de construção de estratégias que fomentam o sucesso escolar dos alunos com deficiência. Ao envolver o aluno com deficiência, busca-se conhecer suas perspectivas sobre como veem o processo de inclusão na escola regular noturna do estado do Ceará e como se sentem em relação à dinâmica inclusiva.

Essa discussão se faz atual e necessária, à medida que o cenário educacional brasileiro, espaço de mudanças, de lutas de classe e, por vezes, de fomento à melhoria do perfil econômico e social de crianças, jovens e adultos, vem se organizando para incorporar a população com deficiência à escola regular e facultarIhes alternativas de interação por meio da educação inclusiva. Para isso, vem albergando esforços no sentido de transformar o espaço escolar num ambiente mais acolhedor e impulsionador de novas formas de relação entre seus alunos com deficiência e sem deficiência.

Essa tarefa é um desafio em construção, que se torna mais instigante quando se pensa na EJA, modalidade educativa destinada a jovens e adultos que não tiveram oportunidade de concluir seus 
estudos na idade esperada, o que representa dezenas de milhões de brasileiros que não conseguiram concluir a Educação Básica e que se encontram fora da escola, muitas vezes em situação de exclusão e vulnerabilidade social.

Assim sendo, este artigo está organizado por esta introdução, onde se encontram destacados a temática estudada e o objetivo geral da investigação. Na sequência, apresenta-se o método, com destaque para o percurso metodológico, o contexto e os sujeitos participantes da investigação. Dando continuidade, tem-se uma reflexão sobre os temas fundantes do estudo, a saber: EJA e Acessibilidade no Brasil, que se constituem basilares para a discussão dos resultados. O estudo é finalizado com as considerações tecidas a partir da investigação e da análise dos resultados, seguida das referências utilizadas.

\section{O MÉTODO}

Este estudo adota a abordagem qualitativa, cuja opção justifica-se por se tratar de uma pesquisa que tem por finalidade a compreensão e a interpretação do fenômeno estudado (CRESWELL, 2014), e é indicada quando foca na dimensão sociocultural expressa através das "crenças, valores, opiniões, representações, formas de relação, simbologias, usos, costumes, comportamentos e práticas" (MINAYO, 2017, p. 2), à luz dos parâmetros que lhe confiram cientificidade.

O estudo de caso, por sua vez, apresentou-se como o método mais apropriado aos objetivos da pesquisa por se configurar como uma "descrição e uma análise intensiva e holística de um fenômeno delimitado como um programa, uma instituição, uma pessoa, um processo ou uma unidade social" (MERRIAM, 1998, p. xiii); assim como representar a "estratégia preferida quando se colocam questões do tipo 'como' e 'por que', quando o pesquisador tem pouco controle sobre os eventos e quando o foco se encontra em fenômenos contemporâneos inseridos em algum contexto de vida real" (YIN, 2010, p. 19).

De posse dessas premissas, utilizou-se, como procedimento de recolha de dados, a entrevista semiestruturada para gestores e professores, por permitir ao entrevistado liberdade para discorrer 
sobre o tema da forma que melhor lhe convier, tanto em relação ao quadro teórico quanto em relação ao que considera mais relevante (AMADO; FERREIRA, 2014); e o questionário para alunos, por ser o instrumento cujas características se adequaram melhor tanto ao propósito da investigação quanto ao público investigado. Para o tratamento dos dados, a opção recaiu sobre a análise de conteúdo, por ser uma abordagem que possibilita a compreensão dos significados culturais construídos nas relações entre as pessoas e as situações, não se restringindo à simples descrição do cotidiano.

\section{População e processo de amostragem}

Este estudo teve como cenário de pesquisa 22 gestores e 33 professores das escolas públicas estaduais de ensino regular do município de Fortaleza, estado do Ceará - Brasil, pertencentes à SER $\mathrm{VI}$, assim como 24 alunos com deficiência incluídos nas turmas de EJA. Para uma melhor compreensão do universo investigado, informa-se que as escolas públicas estaduais de ensino regular do município de Fortaleza totalizavam, à época da pesquisa, 174 unidades, divididas administrativamente em seis regiões, das quais 31 compunham a $6^{\text {a }}$ Região e 11 tinham turmas de EJA; destas, três foram identificadas pelos professores como não tendo alunos com deficiência. A opção por essas escolas se deu em função de contemplarem as características necessárias à objetivação do estudo e por possibilitarem uma amostra dos sujeitos que detêm os atributos necessários que se pretende conhecer.

\section{Análise e interpretação dos dados}

A análise e a interpretação dos dados recolhidos por meio das entrevistas semiestruturadas e dos questionários foram desenvolvidas à luz da análise de conteúdo, alicerçada na proposta de Bardin (2016), cuja utilização prevê três fases essenciais: préanálise, exploração do material e tratamento dos resultados.

No caso das entrevistas, a pré-análise abrangeu a leitura flutuante dos textos transcritos. Por sua vez, a exploração do material 
caracterizou-se pela importação e codificação dos parágrafos por questão e das variáveis de caracterização dos sujeitos. Em sequência, procedeu-se à personalização e organização dos códigos e das variáveis atribuídas e realizou-se a categorização aberta, gerando segmentos amplos (categorias iniciais), a partir da contagem simples e exploratória dos temas abordados nas entrevistas. Dando prosseguimento, fez-se uma associação indutiva para a criação das categorias intermediárias. Dos resultados obtidos, emergiu um rol com os temas mais frequentes e relevantes. Esses eixos foram organizados em categorias intermediárias e finais.

O processo de formação das categorias envolveu a seleção do material, a leitura flutuante e a codificação. A codificação se deu em função da repetição dos temas que, uma vez triangulados com os resultados observados, foram agrupando-se nas categorias definidas. A formulação dessas categorias seguiu os princípios apresentados por Franco (2008) e Bardin (2016): exclusão mútua entre as categorias, homogeneidade dentro das categorias, pertinência, fidelidade, objetividade e produtividade. Concluída a exploração do material, passou-se à análise e discussão dos resultados por categoria.

Em relação aos questionários, a pré-análise abrangeu a tabulação dos dados referentes às questões fechadas e a transcrição das questões abertas, seguida da escolha das categorias que emergiram das questões norteadoras. A exploração do material se processou a partir da escolha do tema como unidade de registro das questões abertas; assim sendo, o texto das questões abertas do questionário foi recortado em unidades de registro, agrupadas por temas (categorias iniciais) e, estes, em categorias finais. Quanto às questões fechadas, a categorização foi definida a priori, quando se estruturou os tópicos que deveriam ser contemplados no questionário. Esse processo contou com a colaboração de informações prévias obtidas com gestores, professores e equipe do Núcleo de Acompanhamento Pedagógico Especializado (NAPE), como forma de assegurar a credibilidade e a adequação do instrumento.

Essa consulta prévia, assim como a produção dos dados e sua posterior organização, fez parte do processo de análise dos resultados, premissa reforçada por Lüdke e André (1986, p. 45), ao 
destacarem que "a análise está presente em vários estágios da investigação, tornando-se mais sistemática e mais formal após o encerramento da coleta de dados".

Para o processo de organização e tratamento dos dados utilizaram-se as potencialidades do software de análise de dados qualitativos, MAXQDA, versão 18.2. A utilização desse software facilitou e enriqueceu as tarefas relacionadas à análise do conteúdo, pois serviu a todas as fases do processo de análise qualitativa, da forma como é descrito por Miles, Huberman e Saldaña (2013).

\title{
EDUCAÇÃO DE JOVENS E ADULTOS: Um processo em construção
}

A EJA é uma modalidade educacional de suma importância para a sociedade contemporânea, que se encontra num processo de mudanças estruturais a serem assumidas pelas populações adultas. Esse processo, no entanto, precisa estar integrado numa visão de educação transformadora, que se encontra validada na definição da Conferência da Organização das Nações Unidas para a Educação, a Ciência e a Cultura (UNESCO), realizada em 1997 na cidade de Hamburgo - Alemanha, donde se define a educação de adultos como

\begin{abstract}
o conjunto de processos de aprendizagem, formal, ou não, graças ao qual as pessoas consideradas como adultas pela sociedade a que pertencem, desenvolvem as suas capacidades, enriquecem os seus conhecimentos e melhoram as suas qualificações técnicas, ou profissionais, ou as reorientam de modo a satisfazerem as suas próprias necessidades e as da sociedade (UNESCO, 1997, p. 7).
\end{abstract}

Para além dessa dimensão ideológica, a conferência da UNESCO sobre Educação de Adultos, realizada na cidade de Belém Brasil, em 2009, reafirma a necessidade de os países se comprometerem com o desenvolvimento de políticas públicas que respondam positivamente aos interesses e projetos das pessoas, em especial daquelas com pouca escolaridade (UNESCO, 2009). Do 
exposto, infere-se que a educação de adultos é de imensa valia para o desenvolvimento das nações e que seus contributos enfatizam a dimensão holística do processo de educação e formação, com vistas à construção da autonomia.

Alcoforado (2014, p. 32-33) corrobora com essa ideia e acrescenta que o movimento de educação e formação ao longo da vida deve contemplar

cinco componentes indissociáveis e dinamicamente conjugados: a construção de uma cidadania planetária ativa e crítica, a garantia de recursos educativos necessários, a necessidade de contextos de vida educativos, a existência de serviços de orientação e aconselhamento e a criação de instituições e serviços que promovam o reconhecimento pessoal e social de saberes construídos nos diferentes espaços e tempos de vida, combatendo o elitismo cognitivo vigente de apenas se valorizarem socialmente os saberes escolares.

Esses componentes levam, invariavelmente, ao desenvolvimento do pensamento reflexivo que, segundo Oliveira (2007, p. 217), "é, efectivamente, entendido como a missão principal da educação de adultos, que consistiria em ajudar pessoas a tornarem-se mais reflexivas na colocação e solução de problemas". Para dar conta de tamanho desafio, é preponderante a ação dos educadores, que têm por missão contribuir para desenvolver o pensamento reflexivo de seus alunos, por meio de atividades que possibilitem aos educandos enfrentarem todas as dificuldades inerentes ao processo de aquisição do conhecimento, com suas múltiplas facetas e pontos de vista.

No Brasil, os desafios em relação à EJA são imensos, pois há um grande contingente de adultos analfabetos. De acordo com o Instituto Brasileiro de Geografia e Estatística (IBGE, 2018), o país abriga a demanda potencial de 11,5 milhões de brasileiros (7\%) não alfabetizados, além de ter cerca de 38 milhões de pessoas consideradas analfabetas funcionais, o que representa três em cada dez jovens e adultos de 15 a 64 anos (PALHARES; DIÓGENES, 2018). 
Esse contexto reflete a história da EJA no Brasil, donde se destaca que as primeiras escolas noturnas brasileiras surgiram no século XIX, com o intuito de alfabetizar os trabalhadores analfabetos, mas, somente com a Revolução de 1930, quando o processo de industrialização se intensificou, é que a EJA começa a delimitar seu espaço na história da educação brasileira, passando a ser dever do Estado o ensino primário integral obrigatório, gratuito, extensivo aos adultos.

Com o direito constitucional garantido, a EJA vai se firmando no cenário nacional. Na década de 1940 é vinculada à educação profissional, com a criação do Serviço Nacional de Aprendizagem Industrial (SENAI), pois precisava-se de mão de obra especializada para promover o desenvolvimento industrial. Nessa época, cerca de $50 \%$ da população brasileira era analfabeta e a estagnação econômica foi relacionada com essa realidade educacional.

Algumas ações foram implementadas para dar cabo de tão caótica situação: a criação do Instituto Nacional de Estudos e Pesquisas Educacionais Anísio Teixeira (INEP), com vistas a incentivar a realização de estudos na área da educação e a criação da Campanha de Educação de Adolescentes e Adultos (CEAA), que visava pensar o material didático específico para a educação de adultos.

No final da década de 1950, o movimento de educação liderado por Paulo Freire aparece no cenário nacional, propondo uma renovação dos métodos e processos educativos, abandonando os processos estritamente auditivos, em que o discurso seria substituído pela discussão e participação do grupo (PAIVA, 1973).

Em 1963, Paulo Freire é encarregado, pelo presidente João Goulart, de organizar e desenvolver o Plano Nacional de Alfabetização de Adultos (PNAA). Esse plano foi extinto pelo Golpe de Estado de 1964 e substituído por programas assistencialistas e conservadores, como a Cruzada Ação Básica Cristã (ABC) e o Movimento Brasileiro de Alfabetização (MOBRAL).

Com a redemocratização do país, em 1985, o MOBRAL é substituído pela Fundação EDUCAR. Em 1990, essa fundação é extinta e a responsabilidade da EJA deixa de ser da União e passa a ser dos municípios. Nesse mesmo ano é criado o Programa Nacional de Alfabetização e Cidadania (PNAC), em resposta ao Ano Internacional 
da Alfabetização, convocado pela UNESCO. Esse programa não avançou, pois carecia de apoio financeiro e político. Segundo Haddad e Di Pierro (2000), a década de 1990 foi marcada pela relativização dos direitos educativos das pessoas jovens e adultas conquistadas anteriormente, passando a ocupar um lugar marginal nas políticas públicas do país.

É nesse contexto que se coloca o desafio de reconfigurar a educação de jovens e adultos que trazem para a escola marcas de muitas situações de exclusão, entre elas a deficiência, e que veem na educação um caminho de desenvolvimento humano e social. Tal reconfiguração ocorreu, legalmente, a partir da Lei de Diretrizes e Bases da Educação Nacional n 9.394 (BRASIL, 1996), quando a EJA passou a ser uma modalidade da Educação Básica, com a definição de que é destinada aos alunos que não tiveram acesso à escola na idade própria, e com gratuidade assegurada pelos sistemas de ensino.

É importante ressaltar que, como assinala Freire (2018), o direito à educação não pode se restringir a estar na escola, é preciso que haja um cuidado com a aprendizagem significativa, capaz de ampliar os horizontes dos alunos, Ihes permitirem tomar consciência do seu estado de opressão e lhes darem condição de se libertar. O autor destaca, ainda, que é igualmente importante considerar os conhecimentos prévios dos alunos, respeitar os saberes socialmente construídos na prática comunitária e discutir a razão de ser de alguns desses saberes em relação ao ensino dos conteúdos, sob pena de não contribuir para a tarefa humanizadora da educação.

No contexto da atualidade, o processo de fortalecimento da EJA está comprometido por ações como o encerramento do Programa Nacional do Livro Didático para a EJA a partir de 2017, seguido da dissolução da Secretaria de Educação Continuada, Alfabetização, Diversidade e Inclusão (SECADI), em 2019, assim como a extinção de vários órgãos de participação popular, deixando os movimentos sociais sem um espaço para direcionarem suas demandas e pautas (Portal De Olho nos Planos, 2019).

Para Paiva, Haddad e Soares (2019), a posição da EJA no atual governo é crítica, pois além de não ter um setor responsável que responda pela modalidade no $\mathrm{MEC}$, os encaminhamentos em relação 
à educação voltam-se para a construção de "uma escola não interessada em desenvolver o espírito crítico dos estudantes, apenas a aprendizagem formal de conteúdos voltados ao mercado de trabalho" (p. 3).

Ao se reafirmar que a EJA deve ser reflexiva, humanizadora, integrada, sustentável, conscientizadora, inclusiva, cumpre-se conhecer em que contexto se efetiva a educação dos jovens e adultos com deficiência matriculados nas escolas brasileiras de ensino regular.

\section{O CONTEXTO DA ACESSIBILIDADE EDUCACIONAL NO BRASIL}

Para se entender a importância da educação inclusiva no Brasil, é imprescindível conhecer os números relacionados à deficiência no país. De acordo com o Censo da Educação Básica (INEP, 2020), o número de alunos com deficiência, transtornos globais do desenvolvimento ou altas habilidades, matriculados em classes comuns ou especiais nas turmas de EJA do país, alcança o patamar de 126.438 alunos. Em simultâneo, o percentual de matrículas desses alunos em classes comuns vem aumentando de forma gradativa. Nas turmas de EJA, em 2017, o percentual de matrículas de alunos incluídos em classe regular era de 51,9\%, passando a 55,3\% em 2018 e 55,4\% em 2019.

A educação inclusiva é, na atualidade, uma questão emblemática para as instituições educacionais e está sempre a agregar novos adeptos, mesmo sabendo-se que formar o aluno com deficiência, com necessidades educacionais diferenciadas, para o sucesso profissional e para uma vida plena, não é incumbência fácil, visto que as instituições educacionais, salvo raras exceções, não estão preparadas para incluí-lo.

Sassaki (1997) destaca que a educação inclusiva principiou a ser oficialmente documentada a partir da década de 1980, inicialmente pela Organização das Nações Unidas (ONU), em 1981, quando proclamou este como sendo o Ano Internacional das Pessoas Deficientes, cujo objetivo era chamar a atenção para a criação de planos de ação que dessem ênfase à igualdade de oportunidades, reabilitação e prevenção de doenças. Em 1982, o ideal de educação 
inclusiva foi confirmado pelo Programa Mundial de Ação para Pessoas com Deficiência e, em 1996, o tema é tratado no documento Normas sobre a Equiparação de Oportunidades para Pessoas com Deficiência (ONU, 1996). Mais recentemente, conforme estabelecido pela ONU no Objetivo de Desenvolvimento Sustentável 4 (ODS 4) da Agenda 2030, que ambiciona assegurar educação inclusiva e equitativa de qualidade e promover oportunidades de aprendizagem ao longo da vida para todos até o final desta década (ONU, 2015), os jovens com deficiência, que têm em comum a privação de oportunidades de aprendizagem na escola formal, bem como a privação de situações favoráveis de desenvolvimento humano, não podem mais ser ignorados.

No Brasil, o tema está contemplado em documentos como o Plano Decenal de Educação para Todos (BRASIL, 1993), que tinha como meta recuperar a escola fundamental no país, na Lei de Diretrizes e Bases da Educação Nacional n0 9.394 (BRASIL, 1996) e, mais recentemente, no Plano Nacional de Educação - Lei $n^{0} 13.005$ (BRASIL, 2014) e na Lei Brasileira de Inclusão da Pessoa com Deficiência (LBI) n. 13.146 (BRASIL, 2015).

Contudo, mesmo tendo assumido o compromisso de fomentar ações inclusivas em diversos documentos legais, o país ainda convive com uma escola regular que, de maneira geral, não está estruturada para acolher a diversidade dos alunos com necessidades educacionais especiais, embora esta mesma escola venha sendo instigada a trabalhar em prol da superação da exclusão, a partir da promoção de uma ação pedagógica que possibilite maiores oportunidades de escolarização, maior entrosamento social e formação para o mundo do trabalho.

Com base nessas premissas, conclui-se que a educação inclusiva é uma realidade pautada por princípios que superam o modelo de atendimento segregado. Essa realidade exige das instituições de ensino uma nova postura, que deve perpassar por ações diferenciadas, capazes de possibilitar a inclusão de todos, indistintamente. Conclui-se, ainda, que agir em prol da acessibilidade educacional abrange pensar a responsabilidade das instituições no que concerne ao desenvolvimento de uma política participativa e à construção de uma cultura inclusiva, assim como considerar o direito 
de todas as pessoas e reconhecer que a exclusão, seja de que natureza for, existe e precisa ser superada.

\section{DISCUSSÃO DOS RESULTADOS}

A partir da análise das informações produzidas sobre o processo de inclusão de jovens e adultos com deficiência no contexto da escola pública do estado do Ceará, do exame de como as ações de apoio a esses alunos têm sido geridas por gestores e professores, assim como das perspectivas dos alunos sobre o processo de inclusão na escola regular noturna, evidenciam-se os seguintes resultados.

No que concerne à gestão escolar para a inclusão nas turmas de EJA, mesmo nas escolas que mais têm investido em formação, estrutura física e parceria com a comunidade, o processo ainda é um desafio de grandes dimensões, pois exige o envolvimento de todos que a compõem, sendo necessário o desenvolvimento de projetos que viabilizem a inclusão em caráter permanente, bem como o incentivo à participação de educadores, alunos e famílias no cotidiano dos jovens com deficiência (VITORINO; GREGO, 2017), pois somente a partir de um esforço conjunto será possível solucionar ou, no mínimo, amenizar as dificuldades vividas por esse público.

Para os gestores das escolas regulares, que atualmente têm o dever de incluir os alunos com deficiência, conforme preconiza a legislação brasileira, é fundamental ter em mente que escolas inclusivas não são aquelas que se limitam a matricular alunos com deficiência, mas são aquelas que se comprometem em criar oportunidades de aprendizagem social, escolar e comunitária para todos.

Nesse sentido, é preciso preparar a comunidade escolar para compreender a identidade e as possibilidades de aprendizagem dos alunos com deficiência, com o fito de criar uma cultura institucional que reconheça o valor das experiências e dos estímulos vividos em comunidade para esses alunos, tanto no que concerne à aprendizagem, quanto ao desenvolvimento pessoal. É necessário, ainda, suplantar a ideia de vitimização desses alunos, assim como investir na formação de professores, de forma que Ihes seja possível compreender que incluir pressupõe o desenvolvimento de práticas 
educativas fundamentadas, que propiciem o desenvolvimento cognitivo, social e intelectual do aluno, independente da sua deficiência.

De acordo com seus depoimentos, pode-se afirmar que vivem um processo de transição, cuja superação de muitos desafios em relação à inclusão e, mais especificamente, à inclusão de jovens e adultos com deficiência é uma exigência inalienável. Em todas as escolas que participaram deste estudo, evidencia-se o entendimento dos gestores entrevistados de que as pessoas com deficiência têm direito à educação, mas que ainda há um longo caminho a ser trilhado por toda a comunidade educativa, pela sociedade civil e pelo governo, com vistas à real efetivação de atitudes inclusivas dentro das escolas.

No grupo dos professores entrevistados, foi assinalada a necessidade de uma série de ajustes, a curto e médio prazos, para que o processo de inclusão se consolide. Dentre eles, destacam-se: disponibilização de recursos econômicos para ajustes estruturais, articulação entre as instituições e os atores sociais envolvidos no processo, conhecimento dos mecanismos legais e institucionais para encaminhar as demandas e envolvimento de todas as instâncias envolvidas no processo educacional. Para tanto, é imprescindível que os órgãos governamentais e as instituições educacionais trabalhem em rede, com vistas à efetivação do processo de inclusão, respeitando o contexto e as especificidades locais.

É necessário, ainda, um investimento significativo no processo de formação dos professores, pois, de acordo com seus depoimentos, a formação de professores é um dos pontos mais críticos no processo de inclusão. Essa constatação se deu a partir da ênfase com que o tema foi destacado pela quase totalidade dos professores entrevistados, em diferentes abordagens da entrevista. Com isso, é possível determinar que a garantia da eficácia da política educacional inclusiva exige uma vinculação entre as políticas educacionais e as políticas de formação de professores, cujo processo formativo, assinalado pelo conteúdo específico de cada área de ensino, não é mais admissível para um contexto mobilizado para o processo de inclusão. Exige, igualmente, um protagonismo por parte do professor na estruturação do seu processo de formação continuada, pois tal 
ação potencializa a mobilização dos saberes docentes e possibilitará a construção de um saber produzido no interior da prática docente, provenientes da investigação da própria prática.

Ainda em relação à ação docente para a inclusão, foram analisados os sentimentos que permeiam o cotidiano dos professores. A partir dos depoimentos dos professores investigados, chegou-se à definição dos sentimentos mais recorrentes: esperança, frustação e medo, que se alternam a depender do contexto de análise. Esse conjunto espelha as incongruências do processo vivido pelos professores e possibilita a estruturação de projetos de apoio emocional ao professor, com vistas a contribuir para sua saúde emocional.

A partir das contribuições destacadas pelos professores, pode-se afirmar que se encontram em um momento marcado por intenso processo de redimensionamento da sua prática docente, pois estão vivendo uma nova realidade, cuja inclusão de alunos com deficiência em suas turmas regulares é prática recorrente. É importante destacar que, apesar das questões relacionadas à formação e aos sentimentos envolvidos na vivência do processo de inclusão, a maioria absoluta dos professores entrevistados entende que a vivência escolar inclusiva amplia em muito as habilidades sociais dos alunos com deficiência, pois thes possibilita efetiva inserção social, além de favorecer a motivação necessária para que participem mais ativamente do processo de ensino e aprendizagem e do mundo laboral.

Em relação à realidade vivida pelos alunos com deficiência incluídos em turmas de EJA da escola pública do estado do Ceará, expressa nos questionários, conclui-se que o processo de inclusão na escola regular, em especial no turno noturno, ainda está aquém do desejado e do realizado nos demais turnos. Um dos fatores é a dificuldade de se ampliar o Atendimento Educacional Especializado (AEE) para os alunos do turno noturno, pois a ausência deste atendimento limita as possibilidades dos alunos com deficiência exclusivamente à ação do professor, e esta, por sua vez, está condicionada a fatores como formação, recursos, apoio dos gestores, entre outros. 
Neste grupo, cujo público investigado são alunos com deficiência intelectual, motora e auditiva, os resultados mostram que, em relação à dimensão arquitetônica e urbanística, a avaliação indica um padrão deficitário, posto que nas áreas de acesso à escola são ínfimas as intervenções e nas áreas internas das escolas só foram feitas intervenções estruturais para atender mais diretamente aos alunos cadeirantes. O mesmo ocorre em relação à acessibilidade atitudinal, cujas barreiras estão presentes nos transportes públicos, no trânsito, nos estacionamentos e na própria falta de informação sobre como interagir com as pessoas com deficiência.

Na opinião dos alunos, a deficiência ainda é uma condição que marginaliza, em particular pelos alunos não deficientes. Quanto ao processo de ensino e aprendizagem, destacam os alunos que a avaliação é um fator de dificuldade, pois ainda vigora o modelo centrado na prova, mesmo reconhecendo-se que os professores estão sempre tentando adaptar os instrumentos de avaliação, considerando as deficiências dos alunos e envidando esforços para que as metodologias de desenvolvimento do conteúdo sejam compatíveis com as formas como o aluno aprende.

Quanto à qualidade de vida e às possibilidades de inserção no mercado de trabalho dos alunos com deficiência que estudam nas turmas de EJA, os alunos participantes do estudo afirmam que a escola é reconhecidamente eficiente na formação cidadã, mas tem dificuldade em preparar o aluno para o mundo do trabalho.

A partir das considerações apresentadas no decorrer deste estudo, admite-se que vários são os obstáculos à inclusão na EJA. No entanto, novos caminhos podem ser traçados, a partir de uma atuação conjunta de todos os sujeitos que direta ou indiretamente exercem influência sobre tal contexto, a saber: legisladores, gestores da esfera pública, comunidade escolar (educadores e educandos), familiares, profissionais de apoio, possibilitando a todos um lugar de fala e uma ação compatível com suas competências.

\section{CONSIDERAÇÕES FINAIS}

Após essa incursão pela EJA, com recorte para a educação de alunos com deficiência, é possível afirmar que estamos vivendo uma 
época em que predominam mudanças contínuas e aceleradas, cujo reflexo na vida de todos os cidadãos se manifestam sob a forma de um processo margeado por incertezas tanto no que concerne ao indivíduo quanto à sociedade.

Tais mudanças têm, em seu epicentro, os avanços tecnológicos que, a cada ano, são mais rápidos e produzem resultados que alteram sobremaneira os sistemas econômicos e, por conseguinte, as estruturas de trabalho. Estas, por sua vez, influem no processo de formação dos indivíduos, que passam a ser cada vez mais exigidos tanto em relação à capacitação profissional quanto em relação à adequação às exigências de um mercado que se constrói e se reconstrói a cada dia, passando a requerer pessoas mais criativas, capacitadas, adaptáveis e com alto nível de instrução e qualificação.

Neste contexto, a educação se reafirma como indispensável ao processo de construção da trajetória do ser humano em busca de um espaço de sobrevivência mais adequado às exigências da sociedade pós-moderna. No entanto, os caminhos não se descortinam de forma rápida e eficiente para atender aos desafios da contemporaneidade. As mudanças estruturais não conseguem incluir todas as pessoas, em todas as suas necessidades e continuam privilegiando alguns, enquanto excluem sistematicamente muitos outros. Tal premissa pode ser observada em todos os níveis de escolaridade e em todas as fases da vida.

Cumpre-se, pois, redesenhar o contexto educacional brasileiro, privilegiando as experiências e saberes dos alunos e intensificando as relações com as comunidades onde o processo educativo se consolida, considerando as seguintes contatações:

- No que diz respeito à gestão, identifica-se a necessidade de os gestores encontrarem alternativas para acolher o aluno e mantê-lo na escola, assumindo o compromisso de estruturar um ambiente favorável à aprendizagem para todos;

- Quanto ao processo de desenvolvimento da aprendizagem, considera-se necessária a constituição de espaços pedagógicos que garantam a permanência do aluno na escola e possibilitem o seu sucesso escolar. Para tanto, há que se buscar uma 
ação pedagógica que considere as especificidades de cada aluno, há que se investir no processo de formação dos gestores e professores das instituições escolares e há que assegurar aos professores o apoio necessário ao desenvolvimento de práticas pedagógicas condizentes com suas necessidades;

- Em relação ao currículo, avalia-se que há inadequações para o perfil dos alunos público-alvo da EJA, constituído por jovens e adultos, em sua maioria trabalhadores, que não puderam concluir a educação básica no tempo certo e que acorrem à escola com o fito de alcançar uma melhor condição social;

- Quanto ao apoio ao aluno, destaca-se a necessidade de ampliação do atendimento educacional especializado aos alunos do turno da noite, no próprio turno, pois a contingência do trabalho os impossibilita de receber $\mathrm{o}$ atendimento no contraturno.

- No que concerne à estrutura física das escolas e às condições de deslocamento em seu entorno, reconhece-se como uma condição estratégica para a inclusão dos alunos com deficiência, que precisa ser redimensionada considerando as dificuldades enfrentadas.

Conclui-se, reforçando a tese de que, mesmo com a ampliação da inclusão na escola regular, assegurada formalmente, ainda é meta a ser alcançada o pleno oferecimento de condições de permanência e sucesso dos alunos com deficiência, em sua trajetória escolar na modalidade EJA. Ao mesmo tempo, destaca-se como pontos positivos dessa investigação: o reconhecimento de gestores e professores no que tange à importância da inclusão escolar em uma sociedade heterogênea e multicultural; a abertura da comunidade escolar para receber o pesquisador e a disponibilidade em contribuir com seus saberes, objetivando ampliar o processo de inclusão; a participação dos alunos, que, mesmo com limitações, estão dispostos a desenvolver potencialidades e superar barreiras; a oportunidade de levar para a escola a discussão sobre o tema da inclusão escolar e 
suscitar nos educadores o desejo de rever suas práticas e buscar novas possibilidades.

\section{REFERÊNCIAS}

ALCOFORADO, Joaquim Luís Medeiros. Uma educação para todos, ao longo e em todos os espaços da vida: desafios para a construção de políticas públicas promotoras de uma cidadania planetária crítica e ativa. In: SILVA, M. F. Mundos Distantes, Diálogos Possíveis: a vida em mosaico. João Pessoa: Ideia, 2014. p. 14-34.

AMADO João; FERREIRA Sónia. A entrevista na investigação em educação. In: AMADO, J. (org.). Manual de investigação qualitativa em educação. Coimbra: Imprensa da Universidade de Coimbra, 2014, p. 207-232.

BARDIN, Laurence. Análise de conteúdo. 3. reimp. da 1. ed. Lisboa: Edições 70, 2016.

BRASIL. Plano Decenal de Educação para Todos. Brasília: MEC, 1993. Disponível em:

http://livros01.livrosgratis.com.br/me002599.pdf. Acesso em: $13 \mathrm{dez}$. 2016.

BRASIL. Lei $n^{0}$ 9.394, de 20 de dezembro de 1996. Estabelece as diretrizes e bases da educação nacional. Diário Oficial da União, Brasília, 23 dez. 1996.

BRASIL. Decreto $n^{0} 7.612$, de 17 de novembro de 2011. Institui o Plano Nacional dos Direitos da Pessoa com Deficiência - Plano Viver sem Limite. Diário Oficial da União, Brasília, 18 nov. 2011.

BRASIL. Lei $n^{0} 13.005$, de 25 de junho de 2014. Aprova o Plano Nacional de Educação (PNE) e dá outras providências. Diário Oficial da União, Brasília, 26 jun. 2014.

BRASIL. Lei n. 13.146, de 6 de julho de 2015. Institui a Lei Brasileira de Inclusão da Pessoa com Deficiência (Estatuto da Pessoa com Deficiência). Diário Oficial da União, Brasília, 7 jul. 2015. 
CRESWELL, John W. Investigação qualitativa e projeto de pesquisa: escolhendo entre cinco abordagens. Porto Alegre: Penso, 2014.

FRANCO, Maria Laura Puglisi Barbosa. Análise de conteúdo. 3. ed. Brasília: Liber Livro, 2008.

FREIRE, Paulo. Pedagogia do Oprimido. Rio de Janeiro: Paz e Terra, 2018.

HADDAD, Sérgio; DI PIERRO, Maria Clara. Escolarização de jovens e adultos. Revista Brasileira de Educação, n. 14, p. 108-130, 2000.

IBGE. Instituto Brasileiro de Geografia e Estatística. Pesquisa nacional por amostra de domicílios contínua. Ano referência 2017. Brasília: IBGE, 2018. Disponível em:

https://biblioteca.ibge.gov.br/visualizacao/livros/liv101657_informati vo.pdf. Acesso em: 10 jun. 2019.

INEP. Instituto Nacional de Estudos e Pesquisas Educacionais Anísio Teixeira. Censo da Educação Básica 2019: resumo técnico, 2020.

Disponível em: http://portal.inep.gov.br/informacao-da-publicacao//asset_publisher/6JYlsGMAMkW1/document/id/6874720. Acesso em: 6 jun. 2020.

LÜDKE, Menga; ANDRÉ, Marli Eliza Dalmazo Afonso de. Pesquisa em educação: abordagens qualitativas. São Paulo: EPU, 1986.

MERRIAM, Sinclair. Qualitative research and case study applications in education. São Francisco: Jossey-Bass, 1998.

MILES, Matthew; HUBERMAN, A. Michael; SALDAÑA, Johnny. Qualitative Data Analysis: A methods sourcebook. 3. ed. Thousand Oaks: Sage, 2013.

MINAYO, Maria Cecília de Souza. Amostragem e saturação em pesquisa qualitativa: consensos e controvérsias. Revista Pesquisa Qualitativa, v. 5, n. 7, p. 01-12, abr. 2017.

OLIVEIRA, Albertina Lima. Desenvolvimento do pensamento reflexivo e educação de adultos: uma revisão de modelos teóricos. In: FONSECA, A. C.; SEABRA-SANTOS, M. J.; GASPAR, M. F. da F. 
(eds.). Psicologia e Educação: novos e velhos temas. Coimbra: Almedina Editora, 2007. p. 217-246.

ONU. Organização das Nações Unidas. Normas sobre equiparação de oportunidades para pessoas com deficiência, 1996. Disponível em: http://www.faders.rs.gov.br/legislacao/6. Acesso em: 22 jan. 2017.

ONU. Organização das Nações Unidas. Transformando nosso mundo: a agenda 2030 para o desenvolvimento sustentável, 2015. Disponível em: https://nacoesunidas.org/wpcontent/uploads/2015/10/agenda2030-pt-br.pdf. Acesso em: 12 mar. 2017.

PAIVA, Jane; HADDAD, Sérgio; SOARES, Leôncio José Gomes. Pesquisa em educação de jovens e adultos: memórias e ações na constituição do direito à educação para todos. Revista Brasileira de Educação, n. 24, e240050, 2019. Disponível em:

https://doi.org/10.1590/s1413-24782019240050. Acesso em: 29 mar. 2020.

PAIVA, Vanilda Pereira. Educação Popular e Educação de Adultos. São Paulo, Brasil: Loyola Editora, 1973.

PALHARES, Isabela; DIÓGENES, Juliana. Três em cada 10 são analfabetos funcionais no país. Jornal 0 Estado de São Paulo, 6 ago. 2018. Disponível em:

https://educacao.estadao.com.br/noticias/geral,tres-em-cada-10sao-analfabetos-funcionais-no-pais,70002432924. Acesso em 19 out. 2018.

SASSAKI, Romeu Kazumi. Inclusão: construindo uma sociedade para todos. Rio de Janeiro, Brasil: WVA Editora, 1997.

UNESCO. Organização das Nações Unidas para a Educação, a Ciência e a Cultura. V Conferência Internacional sobre Educação de Adultos. Lisboa: Ministério da Educação, Secretaria de Estado da Educação e Inovação, 1997.

UNESCO. Organização das Nações Unidas para a Educação, a Ciência e a Cultura. Marco de Ação de Belém. Aproveitando o poder e o potencial da aprendizagem e educação de adultos para 
um futuro viável, 2009. Disponível em:

http://www.unesco.org/fileadmin/MULTIMEDIA/INSTITUTES/UIL/con fintea/pdf/working_documents/Belem\%20Framework_Final_ptg.pdf. Acesso em: 18 jan. 2017.

VITORINO, Stephânia Cottorello; GREGO, Sonia Maria Duarte.

Avaliação enquanto instrumento para nortear a inclusão escolar.

Doxa: Rev. Bras. Psicol. Educ., v. 9, n. 2, p. 200-211, dez. 2017.

YIN, Robert K. Estudo de caso: planejamento e métodos. 4. ed.

Porto Alegre: Bookman, 2010.

Submetido em: Julho/ 2021.

Aceito em: Julho/ 2021. 